\title{
International Orthopaedics
}

(C) Springer-Verlag 1998

\section{Sports-related stress fracture of the clavicle: a case report}

\author{
J. Roset-Llobet, J.M. Saló-Orfila \\ Department of Orthopaedic Surgery and Traumatology, Hospital General de Manresa, Barcelona, Spain
}

Accepted: 30 November 1997

Summary. Stress fracture of the clavicle is extremely rare, even in sports medicine. The authors have treated a young man who, for several years practised a traditional physical activity in which groups of people make human towers by standing on each others shoulders. For the last three years the patient experienced pain in the medial aspect of the right clavicle when he increased the intensity of his training. Bone scintigraphy revealed endosteal thickening which was indicative of a stress reaction. The mechanism of injury, the diagnosis of stress fracture, and a review of the literature are presented.

Résumé. Les fractures par "stress" de la clavicule sont une pathologie extrêmement rare, même chez les sportifs. - Les auteurs presentent un cas sur un jèune homme qui a pratiqué un sport traditionnel pendant plusieurs anneés, consistant, pour un groupe de gens de faire une tour humanine en s'appuyant l'un sur l'épaule de l'autre. Pendant les trois derniers annés le patient a mal au tiers moyen de la clavicule droite lorsqu'il intensifie son entraînement, et de douleur s'arrête a l'issue de la séance athlétique. Quand il a été vu a l'Hôpital, on a confirmé une réaction de "stress" avec une scintigraphie positive et une condensation endostée. Nous précisons le mécanisme du traumatisme, le diagnostic de fracture de fatique, et présentons une révision bibliographique.

\section{Introduction}

Stress fracture and stress reaction are overuse problems that, in athletes, usually occur in the lower

Resprint requests to: J. Roset-Llobet, Servei de COT, Hospital General de Manresa, E-08240 Manresa, Barcelona, Spain limbs. Although this type of lesion has been infrequently described in other locations such as the sternum [18], first rib [2, 12, 15, 19, 21], humerus [1, $29]$, ulna [3, 23], tip of the olecranon $[9,22]$, acromi-

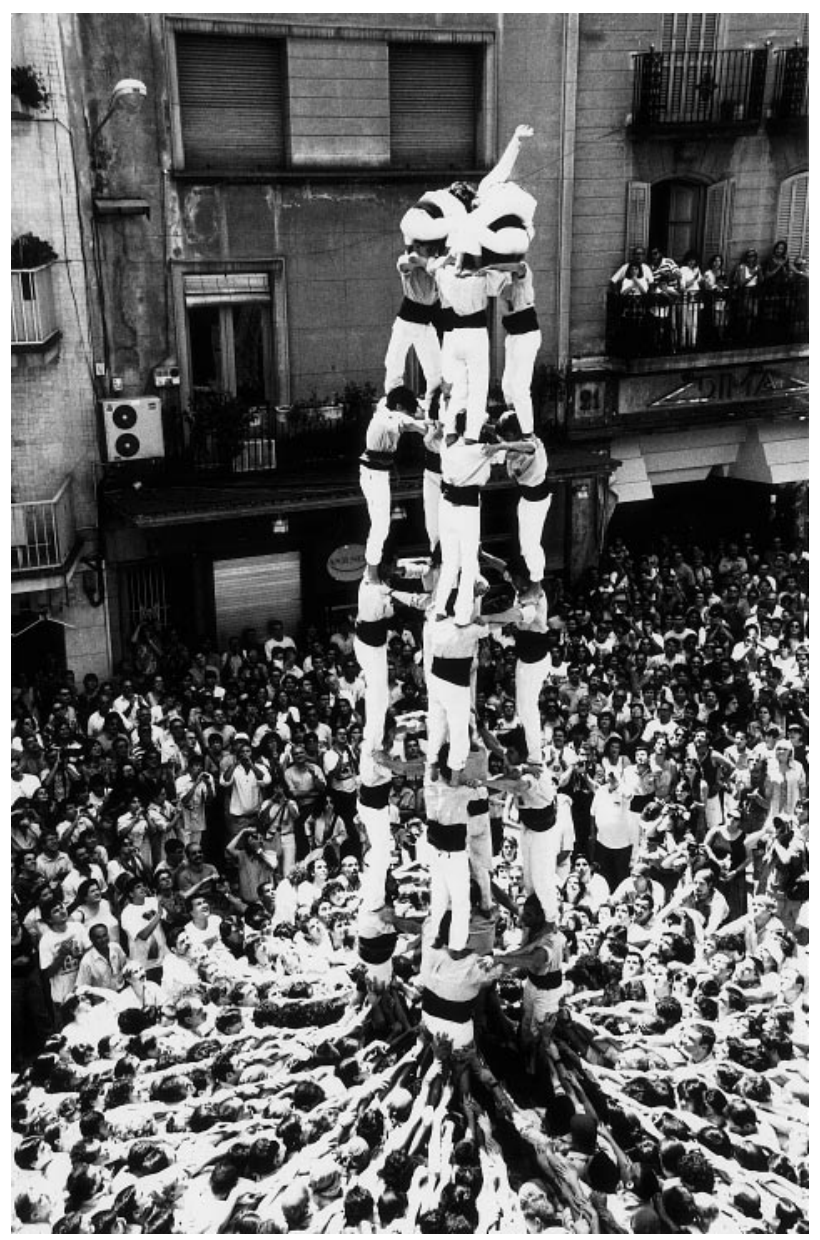

Fig. 1. The human tower; a traditional Catalan physical activity 

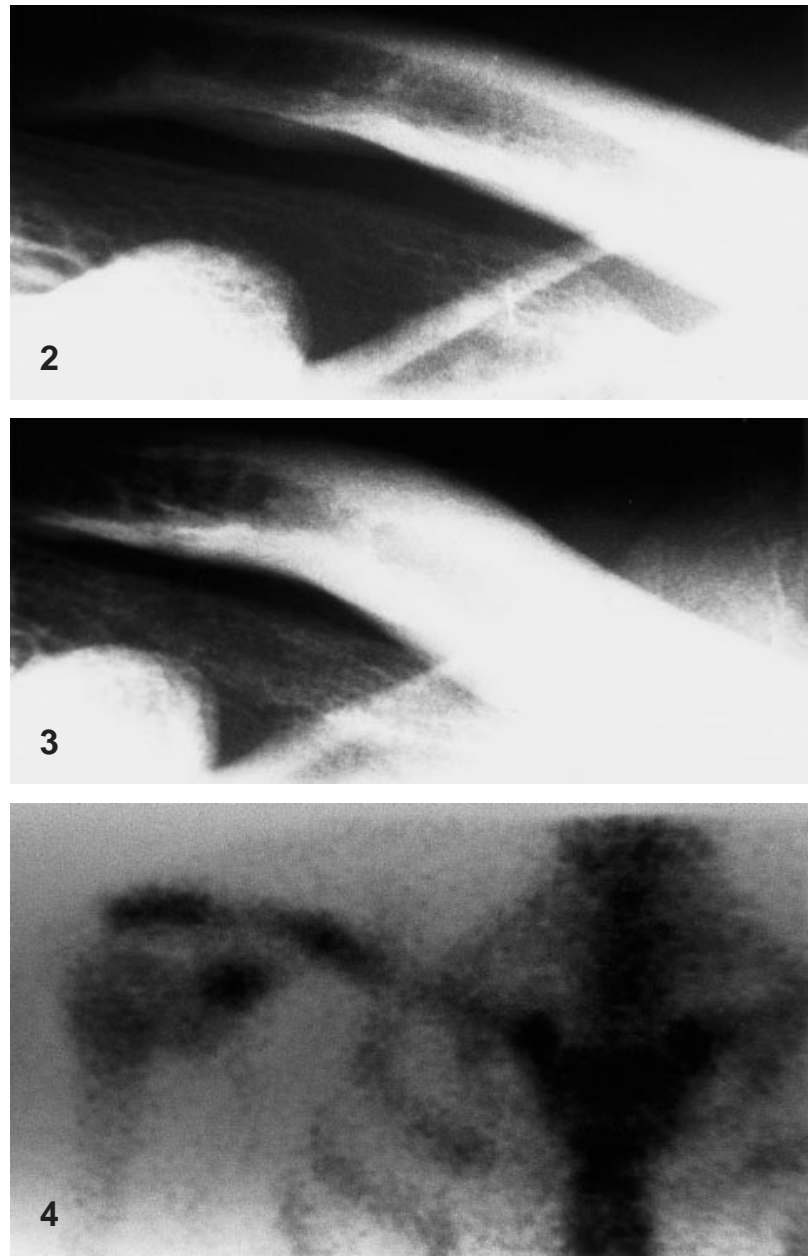

Fig. 2. Normal anteroposterior radiograph of the right clavicle at the onset of pain

Fig. 3. Anteroposterior radiograph of the right clavicle showing cortical hyperostosis and sclerosis

Fig. 4. Technetium-99m bone scan demonstrating a distinct fracture line on the delayed image

um [13] and the coracoid process of the scapula $[4,8$, 30], stress fracture of the clavicle has been reported only during surgery $[7,11,25]$, in the absence of strenuous athletic activity $[17,26]$, or in poorly documented cases [27].

\section{Case report}

A 26-year-old man with a history of three years of clavicular pain had been engaged in a traditional Catalan sport for the previous six years. In this activity, teams of athletes make human towers with up to nine levels, each standing on the shoulders of the level below them (Fig. 1).

The first symptoms appeared at the end of the 1993 athletic season, during which he had rapidly increased his training insensity. He presented with a gradual onset of pain which had progressively worsened with activity. At that point physical examination and plain radiographs were absolutely normal (Fig. 2). The pain disappeared during the winter off-season, and slowly began to recur in a mild form when training commenced. Thereafter, during a normal rotation movement of the shoulder, he experienced acute clavicular pain which lasted for two weeks. He was seen in our hospital three months later, at the end of the 1995 athletic season, when he reported significant pain that had forced him to decrease his level of activity. Physical examination revealed a small palpable mass and marked localised tenderness at the middle third of the right clavicle. There was no oedema or erythema, and no clinical evidence of periosteal thickening. Anteroposterior radiographs of the right clavicle showed cortical hyperostosis and sclerosis; the contralateral side was normal (Fig. 3). Conventional tomography and computerised tomography demonstrated the same hyperostosis but there was no visible fracture. Full blood count, ESR, and biochemical screening were normal. Bone scintigraphy revealed a distinct fracture line in the delayed image phase; the blood pool phase was slightly positive while the angiogram phase was negative (Fig. 4).

A stress fracture of the clavicle was suspected and orthopaedic protection of the shoulder and clavicle was provided. The athlete is now asymptomatic and in full training.

\section{Discussion}

Bone scintigraphy (bone scan) is $100 \%$ sensitive, with no false negatives, but it is not very specific for the differentiation of a stress fracture or reaction from other musculoskeletal abnormalities [28]. For this reason, many aetiologies must be considered in the differential diagnosis following a positive result; these include osteitis, chronic osteomyelitis, osteoma, osteoid osteoma and osteoblastoma [5]. Other rare conditions such as syphilis, Paget's disease, or malignant neoplasms can be discounted as they are not consistent with the evolution of the disorder and the results of complementary investigations [10]. A simple periosteal reaction also warrants consideration, but the clinical findings, the acute increase of the pain without previous trauma and the scintigraphic findings of diffuse non-focal periosteal uptake, mild in intensity, along the bone [31] were not seen in our patient. His scintigraphic appearances are suggestive of a stress fracture even if the process was in a subacute or healing phase [20]. A fracture was not detected by radiograph but it is known that up to $15 \%$ of patients with a positive bone scan never show radiographic changes [6]. A true fracture occurs only when the removal of the cortex is accelerated beyond the capacity of the periosteal reaction to offer adequate reinforcement. For this reason, the radiological demonstration of a fracture line is not necessary for the diagnosis of a stress fracture. In our patient, however, the bone was in the resolution phase and it was doubtful whether the changes represented a moderately severe stress reaction (Grade 2-3) of Jones classification [16] or the subacute-healing phase as described by Martine [20]. We consider that the increased activity in the whole thickness of the clavicle and the distinct fracture line noted on delayed bone scan image were suggestive of a stress fracture in the healing phase. Similar stress fractures of the ribs have been described by several authors $[15,19,21]$.

In the sport of human tower construction, the feet are placed at each side of the neck with the heels on the trapezius muscles and the tarsal bones on the 
clavicles. The weight pushes the clavicle down while the sternocleidomastoid, trapezius, pectoralis major, and deltoid muscles, as well as the coraclavicular and acromioclavicular ligaments, are pulled upon, stressing the point where the feet are pressing. Harrington demonstrated that the critical force for buckling the clavicle is approximately 1-3 times the body weight [14]. In human towers the pressure applied can be over 4 times the body weight and it is sustained for more than 5 minutes, 4 to 6 times a day, 2 to 6 days weekly, during the athletic season of 9 months. It is evident that these forces must be sufficiently stressful to produce a fracture. To the best of our knowledge, this is the first published example of a stress fracture of the clavicle due to athletic activity.

\section{References}

1. Allen M (1974) Stress fracture of the humerus - a case study. Am J Sports Med 12:244-245

2. Barret GR, Shelton WR, Miles JW (1988) First rib fractures in football players. A case report and literature review. Am J Sports Med 16:674-676

3. Bell RH, Hawkins RJ (1986) Stress fracture of the distal ulna. Clin Orthop 209:169-171

4. Boyer DW (1975) Trapshooter's shoulder: stress fractures of the coracoid process. Case report. J Bone Joint Surg [Am] 57:562

5. Brower AC, Sweet DE, Keats TE (1974) Condensing osteitis of the clavicle: a new entity. Am J Roentgenol Radium Ther Nucl Med 121:17-21

6. Bruns BR, Yngve D (1989) Stress reaction and stress fracture. Adv Sports Med Fitness 2:201-222

7. Cummings CW, First R (1975) Stress fractures of the clavicle after a radical neck dissection. Plast Reconstr Surg 55:366-367

8. Daffner RH (1978) Stress fractures: current concepts. Skeletal Radiol 2:221-229

9. De Haven HE, Evarts CM (1973) Throwing injuries of the elbow in athletes. Orthop Clin North Am 4:801-803

10. DiSeegni R, Galea S, Mazzamurro G et al (1979) A case of periostosis of the clavicle in a skeet-shooter. Rays 4: 75-77

11. Dust WN, Lenczner EM (1989) Stress fracture of the clavicle leading to non-union secondary to coracoclavicular reconstruction with Dacron. Am J Sports Med 17:128-129

12. Gurtler R, Pavlov H, Torg JS (1985) Stress fracture of the ipsilateral first rib in a pitcher. Am J Sports Med 13: 277-279
13. Hall RJ, Calvert PT(1994) Stress fracture of the acromion: an unusual mechnism and review of the literature. J Bone Joint Surg [Br] 77:153-154

14. Harrington MA, Keller TS, Deiler JG et al. (1993) Geometric properties and the predicted mechanical behaviour of adult human clavicles. J Biomech 26:417-426

15. Holden DL, Jackson DW (1985) Stress fractures of the ribs in female rowers. Am J Sports Med 13:342-348

16. Jones BH, Harris J, Vinh TN et al. (1989) Exercise-induced stress fractures and stress reaction of bone: epidemiology, aetiology and classification. In: Pandolf KB (ed) Exercise and sport sciences reviews. American College of Sports Medicine Series, vol 17:379-472. Williams \& Wilkins, Baltimore

17. Kaye JJ, Nance EP, Green NE (1982) Fatigue fracture of the medial aspect of the clavicles. An academic rather than atletic injury. Radiology 144:89-90

18. Keating TM (1987) Stress fracture of the sternum in a wrestler. Am J Sports Med 15:92-93

19. Lankenner PA, Micheli LJ (1985) Stress fracture of the first rib. A case report. J Bone Joint Surg [Am] 67: $159-160$

20. Martine JR (1987) The role of nuclear medicine bone scans in evaluating pain in athletic injuries. Clin Sports Med 15:46-58

21. McKenzie DC (1988) Stress fracture of the rib in an elite oarsman. J Sports Med 10:220-222

22. Miller JE (1960) Javelin thrower's elbow. J Bone Joint Surg [Br] 42:788-792

23. Mutoh Y, Mori T, Suzuki Y et al. (1982) Stress fractures of the ulna in athletes. Am J Sports Med 10:365-367

24. Norfray JF, Tremaine MJ, Groves HG et al. (1977) The clavicle in hockey. Am J Sports Med 5:275-280

25. Ord RA, Langdon JD (1986) Stress fracture of the clavicle. A rare late complication of radical neck dissection. J Maxillofac Surg 14:281-284

26. Paul R, Ahonen A, Virtama P et al. (1989) F-18 fluorodeoxyglucose: its potential in differentiating between stress fracture and neoplasia. Clin Nucl Med 14:906-908

27. Pizio Z, Tubek S (1992) Zmceczeniowe zlamanie obojczyka (Stress fracture of the clavicle). Wiad-Lek 45: 477-479

28. Prather JL, Nusynowitz ML, Snowdy HA et al. (1977) Scintigraphic findings in stress fractures. J Bone Joint Surg [Am] 59:869-874

29. Rettig AC, Beltz HF (1985) Stress fracture in the humerus in an adolescent tennis tournament player. Am J Sports Med 13:55-58

30. Sandrock AR (1975) Stress fracture of the coracoid process of the scapula. Radiology 117:274

31. Zwas ST, Elkanovitch R, Frank G (1987) Interpretation and classification of bone scintigraphic findings in stress fractures. J Nucl Med 28:452-457 